\title{
DEVELOPMENT AND IMPLEMENTATION OF COMMUNICATION SKILLS IN DENTISTRY: AN EXAMPLE FROM SOUTH AFRICA
}

\author{
John G White ${ }^{1}$; Christa Krüger ${ }^{2}$; Willem D Snyman ${ }^{3}$ \\ 1. BChD; BChD (Hons); MDP; M.B.A.; DTE; Ph.D. \\ Associate Professor, Department of Dental Management Sciences, School of Dentistry, \\ University of Pretoria
}

2. MBChB; MMed (Psych); MD.

Associate Professor, Department of Psychiatry, School of Medicine, University of Pretoria

3. BChD; MChD (Prost); MChD (Comm Dent); Ph.D.

Professor, Program Manager: Education, School of Dentistry, University of Pretoria

Corresponding author: Prof JG White, School of Dentistry, University of Pretoria, P.O. Box 1266, Pretoria, 0001.

Tel: (+2712) 3192341

Fax: (+2712) 3192146

e-mail: george.white@up.ac.za 


\title{
DEVELOPMENT AND IMPLEMENTATION OF A CURRICULUM FOR TEACHING RELATIONAL COMMUNICATION SKILLS IN DENTISTRY
}

\begin{abstract}
Dental students should realise early in their careers - in dental school - the importance of developing and mastering sound relational communication skills with patients. As a result, the aim of this study was to develop and implement a curriculum in relational communication skills for third year dental students.
\end{abstract}

The methodology employed in the study comprised the following three phases:

Phase I: (i) Evidence from the literature.

(ii) Macro analysis of the South African dental market.

Phase II: (i) Identification of specific and sub-outcomes essential for the dentist to be competitive in the emerging South African dental market.

(ii) Develop a curriculum according to the South African Qualifications Authority format (Purpose, Embedded knowledge, Assessment criteria).

Phase III: (i) Implementation of the curriculum.

Implementation of the curriculum involved a pilot study followed by a pre- and post training cycle. The subjects were 67 third year dental students. The following instruments were employed: A study guide; a case study; an assessment rubric; two questionnaires, namely “Patient’s” feedback and "Dentist's” feedback; a standardised patient. 
Quantitative and qualitative results were obtained.

(i) Quantitative results: The class as a whole scored significantly higher during training cycle 2 compared to training cycle 1 ( $\mathrm{p}<0.0001)$. Both male and female students rated the importance of the respective topics addressed in the curriculum, as rather important - average scores for male and female students were 4.27 and 4.25 , respectively.

(ii) Qualitative results: The important roles of trust, empathy and active listening in establishing a meaningful relationship with a patient, which was conveyed by means of the curriculum, were emphasised by the majority of students.

Key words: Communication skills teaching; curriculum development; customer relationship management; dentist-patient relationship; standardised patient. 


\section{INTRODUCTION}

The point of departure for this study is the contention that a warm, personal and understanding dentist is the primary prerequisite in a patient's appreciation of, and demand for, comprehensive dentistry (1). Comprehensive dentistry comprises all the clinical disciplines of dentistry, namely prosthodontics and implantology, aesthetic (cosmetic) dentistry, preventive dentistry, orthodontics, periodontics and surgery. A private dental practice, in order to be viable, requires patients who are loyal, dentally educated, and as a result prepared to invest in comprehensive dentistry (2; JG White, personal communication). However, a vital, yet often underestimated prerequisite for creating a loyal, dentally educated patient who is prepared to invest in comprehensive dentistry is the dentist's ability to communicate effectively with a patient. The result of effective communication is threefold:

o Firstly, effective communication conveys warmth, interest, respect, empathy and sensitivity towards the patient through a patient-centered approach. As a result of this patient-centered approach, a loyal patient is created through a trusting and safe relationship.

o Secondly, effective communication enables the dentist to deal with patients' expectations, emotions, anxieties and to recognise significant psychosocial factors, leading to more accurate diagnosis and treatment processes, thereby increasing patient satisfaction and -retention and, as a result, the dentist's job satisfaction (3). 
o Finally, with education effective communication creates a patient with an understanding of, or appreciation for, comprehensive dentistry. A patient with an understanding of comprehensive dentistry will demand such and comply with proposed treatment.

In view of the emerging, competitive South African dental market which is characterised by:

(i) patients' need for comprehensive dentistry that is not reflected in their demand for such,

(ii) a rapid decline in the funding of oral care, and

(iii) the cost structure of the average dental practice, the dentist-patient relationship is a crucial factor that has an influence on the viability of the average dental practice in South Africa (SA).

Dental students should be taught in dental school the importance of developing and mastering sound relational communication skills with patients. If students are not taught proper communication skills in dental school, they may develop incorrect habits and pay for their experiences later in their professional careers (4). Dental schools should create competitive dentists - perceived by patients to be different and unique in their relationships with patients and as a result enabled to retain patients. As a result, curricular outcomes must integrate business principles such as customer relationship management (CRM), competitiveness and differentiation with the traditional clinicallyand technique-orientated dental curriculum. 
Until recently, little or no emphasis was placed on the development of interpersonal communication skills because dental students' cognitive and clinical development have always been emphasised. Time restraints and lack of faculty interest also played a part (5; 6). However, an increasing number of proponents of communications skills teaching argue that communication is a core clinical skill rather than an optional extra and should be part of the undergraduate dental curriculum. A recent review done by Aspergren for the Association for Medical Education in Europe concludes that there is overwhelming support for the fact that communication can be taught and learned (7). This, however, requires the development of a relevant, outcomes-based curriculum in relational communication skills. 


\section{METHODOLOGY}

The aim of this study was to develop and implement a curriculum in relational communication skills for third year dental students. It comprised three phases.

\section{Phase I}

During Phase I of the development of an outcomes-based curriculum in relational communication skills, evidence from the literature was combined with a macro-analysis of the South African dental market to identify those specific outcomes and sub-outcomes essential for the dentist to be competitive in the emerging South African dental market.

\section{Phase II}

\section{$\underline{\text { Identification of outcomes }}$}

Given the close relationship between dentistry and medicine, the similar nature of the doctor-patient and dentist-patient interactions, as well as the integration of medical and dental science in the undergraduate dental curriculum at the University of Pretoria, it was decided to explore the literature in terms of currently used doctor-patient communication models in medicine and determine whether such models could be applied in dentistry.

The five currently used models of doctor-patient communication $(8 ; 9 ; 10 ; 11 ; 12)$ were combined in the Kalamazoo Consensus Statement (13) which represents the essential elements of physician-patient communication. However, the Kalamazoo Consensus Statement was further developed in this study by combining it with the Competency Keys: Actualizing the Gold Standards of Communication Skills (14). Furthermore, as a 
result of the first author's 25 years' personal experience as dentist of the South African dental market, a few "dentistry-specific" adjustments were made to the combined model.

This developmental process resulted in those required specific outcomes and suboutcomes essential for the dentist to be competitive in the emerging South African dental market in terms of relational communication skills (Table 1, below). 
Table 1 Outcomes and sub-outcomes essential for the dentist to be competitive in the emerging South African dental market

\begin{tabular}{|c|c|}
\hline Specific outcomes & Sub-outcomes \\
\hline $\begin{array}{l}\text { Opening the interview } \\
\text { (Create safe environment) }\end{array}$ & $\begin{array}{l}\text { - } \text { Greets patient } \\
\text { - } \text { Obtains patient's name } \\
\text { - Introduces self } \\
\text { - } \quad \text { Attends to patient's physical comfort (here and throughout interview) } \\
\text { - Identifies and confirms patient's chief complaint }\end{array}$ \\
\hline $\begin{array}{l}\text { Gathering information: Structuring the interview } \\
\text { (Explain interview process) }\end{array}$ & $\begin{array}{l}\text { - Negotiates an agenda for consultation } \\
\text { - Attends to timing }\end{array}$ \\
\hline $\begin{array}{l}\text { Gathering information: Exploration of problems } \\
\text { (Determine chief complaint) }\end{array}$ & $\begin{array}{l}\text { - Encourages patient to give history of chief complaint } \\
\text { - Uses open questioning technique(s) } \\
\text { - Uses closed questioning technique(s) } \\
\text { - Listens attentively (no interruptions; allow time for patient to think } \\
\text { before answering) } \\
\text { - Facilitates patient's responses (use of encouragement, silence, } \\
\text { - Clarifies patient's statements which are vague and need amplification } \\
\text { - Summarises at end of a specific line of inquiry to verify own } \\
\text { interpretation of what patient has said to ensure no important data was } \\
\text { omitted }\end{array}$ \\
\hline $\begin{array}{l}\text { Understanding the patient's perspective } \\
\text { (Determine expectations, psychosocial issues \& emotions) }\end{array}$ & $\begin{array}{l}\text { - Determines patient’s expectations regarding each problem } \\
\text { - Picks up verbal cues (patient's need to contribute information/ask } \\
\text { questions; information overload; distress) } \\
\text { - Picks up non-verbal cues (patient's need to contribute information/ask } \\
\text { - } \text { questions; information overload; distress) } \\
\text { - Encourages expressions of feelings } \\
\text { - Accepts legitimacy of patient's views/beliefs (non-judgmental) }\end{array}$ \\
\hline $\begin{array}{l}\text { Sharing information } \\
\text { (Treatment plan presentation) }\end{array}$ & $\begin{array}{l}\text { - Discusses treatment options } \\
\text { - Discusses consequences of not proceeding with treatment plan (in non- } \\
\text { threatening manner) } \\
\text { - Provides information about procedures, processes, benefits \& } \\
\text { advantages, value \& purpose) } \\
\text { - Uses easily understood language (avoids or adequately explains } \\
\text { technical terminology) } \\
\text { - Shares own thoughts \& ideas }\end{array}$ \\
\hline
\end{tabular}




\begin{tabular}{|c|c|}
\hline $\begin{array}{l}\text { Reaching an agreement on treatment plan(s) } \\
\text { (Treatment plan acceptance) }\end{array}$ & $\begin{array}{l}\text { - Obtains patient's view of need for action (perceived benefits) } \\
\text { - Negotiates mutually acceptable treatment plan (encourages patient to } \\
\text { make choices; address concerns) } \\
\text { - Elicits patient's understanding about treatment plan(s) } \\
\text { - Takes patient's lifestyle, beliefs, cultural background and abilities into } \\
\text { - Encourages patient to be involved in implementing treatment plan (to } \\
\text { - } \text { take responsibility and be self-reliant) } \\
\text { - Asks about patient's support network for decision-making }\end{array}$ \\
\hline Close the interview & $\begin{array}{l}\text { - Summarises session briefly } \\
\text { - Contracts with patient regarding next step(s) for patient and } \\
\text { - } \text { dentist } \\
\text { - Explains possible unexpected outcomes and safety-nets } \\
\text { appropriately }\end{array}$ \\
\hline $\begin{array}{l}\text { Nurture the relationship } \\
\text { (Employ relationship building blocks) }\end{array}$ & $\begin{array}{l}\text { - Demonstrates interest } \\
\text { - Demonstrates respect } \\
\text { - Communicates warmth } \\
\text { - Demonstrates appropriate non-verbal behaviour (for example eye } \\
\text { contact, posture \& position, movement, facial expression, use of voice) } \\
\text { - Reading, writing, use of computer do not interfere with } \\
\text { - dialogue/rapport } \\
\text { - Shows empathy with patient } \\
\text { - Beals sensitively with embarrassing and disturbing topics } \\
\text { Bith the patient }\end{array}$ \\
\hline
\end{tabular}




\section{Development of a Curriculum in Relational Communication Skills}

The curriculum was developed and structured according to the format required by the South African Quality Authority (SAQA) and compiled as a study guide. Each student was issued with a copy of the study guide. The structure of the curriculum comprises the following three dimensions:

o The purpose

The purpose of a curriculum in relational communication skills was stated.

- Embedded knowledge

It represents the supporting evidence from the literature.

o Assessment criteria were derived from the outcomes and sub-outcomes.

The assessment criteria were compiled as an assessment rubric and employed by the standardised patient (SP) as assessment instrument* during assessment of students' relational communication skills.

*(The initial assessment rubric was statistically analysed to investigate and confirm its construct validity and internal consistency. This resulted in a refined and adjusted (final) assessment rubric. The development of this assessment rubric will be described in a separate article to follow). 


\section{Phase III}

Implementation of the curriculum

Implementation of the curriculum comprised the following:

- A pilot study

- $\quad$ Pre- and post-training cycles

\section{$\underline{\text { Pilot study }}$}

A pilot study was conducted with 10 fourth-year and 10 second-year students before commencement of the study. The purpose of this pilot study was twofold:

o To evaluate the design of the research process, the SP's use of the assessment rubric and the appropriateness of two of the instruments, namely the "Patient's" feedback and the "Dentist's" feedback.

o To ensure the eventual "richness" and trustworthiness of the data collected.

The pilot study confirmed the following:

o The SP experienced the assessment rubric as an appropriate and user-friendly instrument to assess students’ relational communication skills.

o The questionnaire: "Patient's" feedback, employed as assessment instrument by the SP, complemented the rubric as assessment instrument.

o The six categories of the original questionnaire: "Dentist's" feedback, that required open-ended, qualitative feedback by the student acting as “dentist”, was experienced as inadequate. In order to ensure "richness" and trustworthiness of data, students' open-ended, qualitative feedback needed to be enhanced by a quantitative rating 
scale. As a result, a qualitative data analysis process was employed to develop a quantitative rating scale to complement the original questionnaire.

\section{Pre- and post training cycles}

The curriculum was implemented by means of a pre-and post training cycle comprising five steps (Table 2, below). The rationale for this design was the following:

o A pre- and post-training cycle enabled the researcher to evaluate the effect of the proposed dental educational research intervention on students' observable relational communication skills;

o In order to enhance student-centered, problem-oriented learning, the design ensured the exposure of students to an experiential learning strategy complemented by a didactic teaching strategy (Steps $1 \& 3$ ). The purpose of first exposing students to an experiential learning strategy (Step 1) was to stimulate students affectively - to "experience the experience" - about the nature and process of conducting an interview. As a result, students' identification with, and realisation of the importance of the theoretical evidence supporting communication skills teaching were enhanced. The evidence behind communication skills teaching, the cognitive aspects as well as the required communication skills were presented during the didactic teaching strategy (Step 3). The experiential teaching strategy was repeated after the didactic teaching strategy to enable students to functionalise the acquired skills through repetitive practice (Step 4); 
o Evaluation of students' relational communication skills by the SP (Steps $2 \& 5$ ) by means of the assessment rubric ensures transparent, objective, reliable and credible assessment.

\section{Subjects}

A cohort of 67 third year dental students comprised the subjects of the study. The demographics of the subjects were as follows: the majority $(n=42 ; 63 \%)$ was female. Forty eight students (72\%) were White, 12 students (18\%) were African and seven students (10\%) were Asian. The average age of the group was 21.8 years (male $=22.8$ years; female $=21.2$ years). The cohort of 67 students was divided into 16 smaller groups of four students each and one group of three students.

\section{Instruments}

- Study guide

A study guide was compiled and each student was issued with a copy.

- Case study

A case study was developed which represented a clinical scenario comprising the full scope of biopsychosocial skills required during the dentist-patient interview. The clinical scenario represented a patient with the following diagnosis: a carious lesion on the right maxillary first premolar; a defective restoration on the left maxillary central incisor; a discoloured right maxillary central incisor; gingivitis and an impacted left mandibular wisdom tooth. Each student interviewed the SP by means of the case study. 
- Assessment rubric

The identified outcomes and sub-outcomes were converted into a logical and sensible structure or rubric for teaching and assessing dental students' relational communication skills. The rubric comprised seven communication tasks. For each of the seven communication tasks, various skills were listed, resulting in a total of 43 skills.

- “Patient’s" feedback

The questionnaire: "Patient's" feedback was designed to focus particularly upon the relationship between dentist and patient, patient understanding, -loyalty and -agreement. The SP, as "patient”, rated her experiences of the "dentist's” relational communication skills during her interview with each student on a five-point Likert scale by means of this questionnaire (15). Likert scales are commonly used to measure attitude, providing 'a range of responses to a given question or statement' (16).

\section{- “Dentist's” feedback}

Each student provided quantitative and qualitative feedback about his/her experience as “dentist” during the interview with the SP on a five-point Likert scale and by answering open-ended questions, respectively.

- Standardised patient

A professional actress was trained as SP to portray the case study (clinical scenario) in a consistent, reproducible and measurable manner (17). To assist the SP in understanding the nature of the dental scenario and its presenting signs and symptoms, written case 
notes were prepared for the SP to review. During training of the SP, the assessment rubric (Table 2, below) served to educate her about the nature of the dentist-patient interaction. The SP was provided with guided feedback as she rehearsed the desired physical and verbal responses during her interaction with the "dentist." 
Table 2 Design of the study: Pre- and post- training cycles

\begin{tabular}{|c|c|c|c|c|c|}
\hline \multirow{2}{*}{$\begin{array}{l}\text { Pre-training } \\
\text { cycle } \\
\text { (Training } \\
\text { cycle 1) }\end{array}$} & Step 1 & $\begin{array}{l}\text { Experiential learning } \\
\text { opportunity (“experience } \\
\text { the experience”) }\end{array}$ & $\begin{array}{l}\text { Role play } \\
\text { case study with } \\
\text { SP }\end{array}$ & $\begin{array}{l}\text { Video recordings of } \\
3^{\text {rd }} \text { year dental } \\
\text { students' base line } \\
\text { communication } \\
\text { skills }\end{array}$ & \\
\hline & Step 2 & & & $\begin{array}{l}\text { Evaluation of } 3^{\text {rd }} \\
\text { year dental } \\
\text { students' base line } \\
\text { communication } \\
\text { skills }\end{array}$ & $\begin{array}{l}\text { Evaluation by } \\
\text { SP by means } \\
\text { of the } \\
\text { Assessment } \\
\text { rubric }\end{array}$ \\
\hline & Step 3 & $\begin{array}{l}\text { Cognitive evidence } \\
\text { by means of didactic } \\
\text { teaching }\end{array}$ & $\begin{array}{l}\text { Lecture } \\
\text { Videos } \\
\text { Study guide }\end{array}$ & $\begin{array}{l}\text { Developing } 3^{\text {rd }} \text { year } \\
\text { dental students' } \\
\text { communication } \\
\text { skills by teaching }\end{array}$ & $\begin{array}{l}\text { Self- \& Peer } \\
\text { evaluation }\end{array}$ \\
\hline $\begin{array}{l}\text { Post- } \\
\text { training } \\
\text { cycle } \\
\text { (Training } \\
\text { cycle 2) }\end{array}$ & Step 4 & Experiment/practice & $\begin{array}{l}\text { Experiential } \\
\text { learning/role } \\
\text { play with } \\
\text { SP }\end{array}$ & $\begin{array}{l}\text { Video recordings of } \\
3^{\text {rd }} \text { year dental } \\
\text { students' newly } \\
\text { developed } \\
\text { communication } \\
\text { skills }\end{array}$ & \\
\hline
\end{tabular}




\begin{tabular}{|l|l|l|l|l|}
\hline & & & & Evaluation of 3 \\
Std & Evaluation by \\
year dental & SP by means \\
students' newly & of the \\
& developed & Assessment \\
& communication & rubric \\
& & skills & \\
& & & & \\
\hline
\end{tabular}




\section{RESULTS}

\section{Quantitative Results}

Both male and female students (including the class as a whole) scored significantly higher during training cycle 2 compared to training cycle 1 ( $\mathrm{p}<0.0001)$. Both male and female students rated the importance of the respective topics addressed in the curriculum, as rather important - average scores for male and female students were 4.27 and 4.25 on a five-point Likert scale, respectively.

\section{Qualitative Results}

Examples of students’ qualitative feedback are represented in Tables 4 - 7. Table 4 (below) indicates that by role-playing a structured interview, students' confidence to interact in a relaxed way with the "patient” was enhanced.

\section{Table 4 Role-play improved students’ confidence}

- "The visual aids helped to give more information to the patient. The structure given in the lecture helped me to be more confident. I am more relaxed now compared to the first time.”

- "This practice helped us and enabled us to approach the patient and also helped us to improve our confidence and thus be able to express ourselves.”

The important roles of trust, empathy and active listening in establishing a relationship with a patient, were emphasised by most of the students (Table 5, below). 


\section{Table 5 Role of trust, empathy and active listening}

- $\quad$ "I think it is important that we are given things that establish trust. Trust is very important. As a dentist, the patient must trust you.”

- " "I have realised that listening ATTENTIVELY makes it easier for me to find out more about my patient."

- "You have to have a patient-centered approach. LISTEN. See the PERSON behind the teeth!"

Third year dental students positively perceived the learning of relational communication skills (Table 6, below).

\section{Table 6 Students' perceptions about their learning of communication skills}

- " $\quad$ It was an excellent learning experience!”

- “Extremely enlightening!”

- $\quad$ "The video was extremely helpful. I was able to realise and see my mistakes. It's much better seeing your mistakes than being told by an examiner.”

- “This method is definitely the best way to teach communication skills. Good to do video analysis afterwards.”

Table 7 (below) represents students' negative comments with regard to the communication skills teaching. 
Table 7 Students' negative comments about their experiences

- "Communication could be more effective with a broader background of dentistry"

- "We need more practice with different patients."

\section{DISCUSSION}

This study describes a communication skills course that emphasises a skills-based approach: $3^{\text {rd }}$ year dental students conducting an interview with a standardised patient on the basis of a realistic clinical scenario. All the interviews were video recorded.

Previous research indicated that, for many dental schools in the United States and the United Kingdom, communication skills training involved didactic teaching practices and few opportunities for in-vivo practices $(18 ; 19)$. However, this study confirms that skills, attitudes and knowledge can be discussed, lectured and practised in the classroom, but communication skills develop with practice, feedback and repetitive performance (20).

Students rated the course in relational communication skills teaching highly in terms of its perceived educational value, relevance and enjoyment. Such a favorable rating is consistent with previous studies of communication skills programs in dentistry (3; 21; 22; 23; 24; 25; 26). Students' positive evaluations may be as a result of the following: 
o The methodology followed - a skills-based, experiential teaching approach facilitates students' reflection on their learning experiences during communication skills teaching.

o By experiencing the role of “dentist" and "patient” (Table 2, Step 3), students' experiential learning processes were enhanced.

o Self-evaluation, peer evaluation (Table 2, Step 3) and evaluation by the SP (Table 2, Steps 2 \& 5), enhanced the experiential learning process and ensured positive reinforcement of the message as well as the retention of skills.

o Students gained confidence and expertise as the study progressed, which will hopefully make the transition to the clinical setting with real patients easier.

o The use of a realistic, clinically-based case study gave students exposure to psychosocial and lifestyle factors relevant to oral disease processes (3; 27).

Although Froelich and Bishop (28) have noted that the ability to communicate skillfully and with purpose rarely occurs as a gift, but is learned, the reality is that the term “communication skills” is perceived as an intrinsic part of an individual's personality, his/her cognitive functioning and social experience (3). Therefore, although the majority of students realise the importance of relational communication skills' contribution to the dentist-patient relationship, communication skills teaching may suggest to students that they will be learning skills that they already possess, or that which is merely common sense or instinctively acquired. Furthermore, the fact that students are often required to make changes to aspects of their appearance and behaviour that are of a highly personal nature, makes communication skills teaching and training very challenging. As a result, 
initial resistance and skepticism were addressed by stressing the fact that the term "communication skills" was referring to the dentist-patient interaction, with the aim to create an educated, appreciative patient who will demand comprehensive dentistry and accepts proposed treatment.

Finally, the gathering of information from the "patient" requires a shift form dentist-

centered communication to patient-centered communication (3). This was clearly demonstrated during this research project, when before training - during training phase 1 (Table 2) - students tended to focus on the patient (disease) to the exclusion of the person (expectations, psychosocial issues and emotions). The feedback sessions by means of the video-feedback provided an ideal opportunity to address this tendency among students.

\section{Strengths of the study}

Among the strengths of the study are:

o The large number of participants $(n=67)$.

o The small sizes of the groups of students (16 groups of four students each and one group of three students).

o The standardised teaching method (rated 4.18 and 4.26 on a five-point Likert scale by male and female students, respectively).

o The design of the study in a pre- and post-training cycle. 


\section{Limitations of the study}

A limitation of the study could be that the same SP, who might have had a vested interest in the students' improvement, assessed the students' communication skills during both the pre- and post-training cycles. Furthermore, that the study relied on "subjective" ratings and responses by the SP and students. However, the design of such a project - in order to achieve the required outcomes - is critical in view of the demanding nature of communication skills training in terms of resources such as time and manpower. The first author, as a result of his close involvement and experience of students' development during this project (as well as two similar, subsequent communication skills teaching projects) was convinced that by far the majority of responses - both qualitative and quantitative - were genuine and reliable ratings and responses by the SP and students.

Finally, some might question the outcomes and sub-outcomes (Table 1) as not "dentistryspecific.” The authors attempted to proof above (Phase II of Methodology), that the outcomes and sub-outcomes were indeed related to dentistry.

\section{CONCLUSION}

The emerging South African dental market necessitates more effective dentist-patient interactions that will result in improved outcomes in terms of patient- and dentist satisfaction, patient loyalty and -retention and patients' compliance with proposed treatment plans. 
In view of the emerging, competitive South African dental market, South African dentists will need to be able to increase the number of their patients who have a demand for comprehensive dentistry in order to ensure a viable career in dentistry. Consequently, the dentist must be equipped with relational communication skills that will create a loyal, dentally educated patient. Furthermore, the future South African dentist must be equipped with skills both to elicit and to listen to patients' "stories" (for example their expectations, psychosocial issues and emotions). Finally, the future South African dentist must be able to effectively and clearly present comprehensive treatment plans to ensure acceptance and compliance by the patient.

More effective dentist-patient interactions in terms of accuracy, efficiency, respect, trust, warmth and empathy will hopefully result in collaboration and reduced conflicts and complaints between dentist and patient. 


\section{REFERENCES}

1. Wentz FM. Patient motivation: A new challenge to the dental profession for effective control of plaque. Journal of the American Dental Association 1972: 85: 887 $-891$.

2. McCombs PR. Crossing the Rubicon. Preparing residents for professional life after residency. Eur J Dermatol 2004: 14: 371 - 374.

3. Hannah A, Millichamp CJ, Ayers KMS. A communication skills course for undergraduate dental students. J Dent Educ 2004: 68(9): 970 - 977.

4. Davis EL, Tedesco LA, Nicosia NE, Brewer JD, Harnett TE, Ferry GW. Use of videotape feedback in a communication skills course. J Dent Educ 1988: 52(3): 164 166.

5. White JG. Dentistry in the 21st century. South African Dental Journal 2002: 57 (3): $107-109$.

6. Kurtz SM. Doctor-patient communication: Principles and practices. Can J Neurol Sci 2002: 29: suppl (2): 23 - 29.

7. Aspergren K. Teaching and learning communication skills in medicine: A review with quality grading of articles. Med Teach 1999: 21(6): 563 - 570 .

8. Novack DH, Dubé C, Goldstein MG. Teaching medical interviewing: A basic course on interviewing and the physician-patient relationship. Arc Intern Med 1992: 152: $1814-1820$.

9. Keller VF, Carroll JG. A new model for physician-patient communication. Patient Educ Couns 1994: 23: 131 - 140. 
10. Stewart M, Belle Brown J, Weston WW, McWhinney IR, McWilliam CL,

Freeman TR. Patient-Centered Medicine: Transforming the Clinical Method: Thousand Oaks, CA:Sage, 1995.

11. Kurtz S, Silverman J, Draper J. Teaching and Learning Communication Skills in Medicine. Oxford: Radcliffe Medical Press, 1998.

12. Makoul G. The SEGUE Framework for teaching and assessing communication skills. Patient Educ Couns 2001: 45: 23 - 34.

13. Kalamazoo Consensus Statement. Essential elements of communication in medical encounters: In: Bayer-Fetzer Conference on Physician-Patient Communication in Medical Education. Acad Med 2001: 76 (4): 390 - 393.

14. Guenther MK. Actualizing the gold standard of communication skills. In: ASPE Workshop; University of Michigan, 2003.

15. Cohen L, Manion L, Morrison K. Research Methods in Education. 5th ed. London: RoutledgeFalmer, 2000.

16. Jamieson S. Likert scales: How to (ab)use them. Med Educ 2004: 38: 1217 1218.

17. Zraick RI, Allen RM, Johnson SB. The use of standardised patients to teach and test interpersonal and communication skills with students in speech-language pathology. Adv Health Sci Educ Theory Pract 2003: 8: 237-248.

18. McGoldrick PM, Pine CA. A review of teaching of behavioural sciences in the United Kingdom dental undergraduate curriculum. Br Dent J 1999: 186: 576 - 580.

19. Yoshida T, Milgrom P, Coldwell S. How do U.S. and Canadian Dental Schools teach interpersonal communication skills? J Dent Educ 2002: 66 (11):1281 - 1288. 
20. Beckman HB, Frankel RM. Training practitioners to communicate effectively in cancer care: It is the relationship that counts. Patient Educ Couns 2003: 50: 85 - 89.

21. Linton JC, McCutcheon WR, Stevenson JM. Teaching behavioural principles to dental students: A pilot course. J Dent Educ 1975: 39: 149 - 151.

22. Jackson E. Convergent evidence for the effectiveness of interpersonal skill training for dental students. J Dent Educ 1978: 42: 517 - 523.

23. Runyon HL, Cohen LA. The effects of systematic human relations training on freshman dental students. Journal of American Dental Association 1979: 98: 196 201.

24. Gorter RC, Eijkman AJ. Communication skills training courses in dental education. Eur J Dent Educ 1997: 1: 143 - 147.

25. Pine CM, McGoldrick PM. Application of behavioural sciences teaching by UK dental undergraduates. Eur J Dent Educ 2000: 4: 49 - 56.

26. Croft P, White DA, Wiskin CMD, Allan TF. Evaluation by dental students of a communication skills course using professional role-players in a UK School of Dentistry. Eur J Dent Educ 2005: 9: 2 - 9.

27. Silverman J, Kurtz S, Draper J. Skills for Communicating with Patients. Abingdon, UK: Radcliffe, Medical Press, 1998: 1 -16.

28. Froelich RE, Bishop FM. Medical Interviewing: A Programmed Manual. 2nd ed. St.Louis: Mosby, 1972. 